\title{
Orbital Compartment Syndrome: How a Young Man's Vision was Saved by the Timely Actions of an Emergency Medicine Physician
}

\author{
Jessica Houck ${ }^{1}$, Rohan Mangal ${ }^{2}$, Chrissy Vandillen ${ }^{3}$, Latha Ganti ${ }^{4}$, Bryan C. Sleigh ${ }^{5}$ \\ 1. Emergency Medicine, University of Central Florida College of Medicine / Hospital Corporation of \\ America Graduate Medical Education (HCA GME) Consortium, Kissimmee, USA 2. Emergency Medicine, \\ John Hopkins University, Baltimore, USA 3. Emergency Medicine, St. Cloud Regional Medical Center, St. \\ Cloud, USA 4. Emergency Medicine, Envision Physician Services, Orlando, USA 5. Emergency Medicine, \\ Mercer University School of Medicine, Macon, USA
}

$\square$ Corresponding author: Rohan Mangal,rmangal2@jhu.edu

Disclosures can be found in Additional Information at the end of the article

\section{Abstract}

In the following case presentation, a young man who incurred orbital compartment syndrome (OCS) from physical trauma significantly improved from timely lateral canthotomy. Lateral canthotomy is recommended to be performed as soon as possible to avoid permanent vision loss, which is the most feared complication associated with orbital compartment syndrome. This procedure completely restored vision in the patient and permitted prompt discharge.

Categories: Emergency Medicine, Ophthalmology

Keywords: orbital compartment syndrome, lateral canthotomy

\section{Introduction}

Orbital compartment syndrome (OCS) is an ophthalmic emergency that describes an increase in intraorbital volume and pressure, resulting in retinal ischemia [1,2]. Within two hours, patients may experience irreversible vision loss, unless the condition is quickly recognized and treated.

In situations of OCS, emergency physicians often do not have an ophthalmologist accessible to emergently treat patients [3]. To promptly treat this condition, lateral canthotomy is a relatively simple procedure that is recommended to prevent vision loss.

Received 06/04/2019

Review began 06/16/2019 Review ended 06/20/2019 Published 07/01/2019

\section{(C) Copyright 2019}

Houck et al. This is an open access article distributed under the terms of the Creative Commons Attribution License CC-BY 3.0., which permits unrestricted use, distribution, and reproduction in any medium, provided the original author and source are credited.

\section{Case Presentation}

A 32-year-old male presented to an outside emergency department (ED) one hour after being physically assaulted, suffering from multiple blows to his face. On our exam, the patient had significant right periorbital swelling with proptosis (Figures 1-2).
How to cite this article

Houck J, Mangal R, Vandillen C, et al. (July 01, 2019) Orbital Compartment Syndrome: How a Young

Man's Vision was Saved by the Timely Actions of an Emergency Medicine Physician. Cureus 11(7): e5057. DOI 10.7759/cureus.5057 


\section{Cureus}

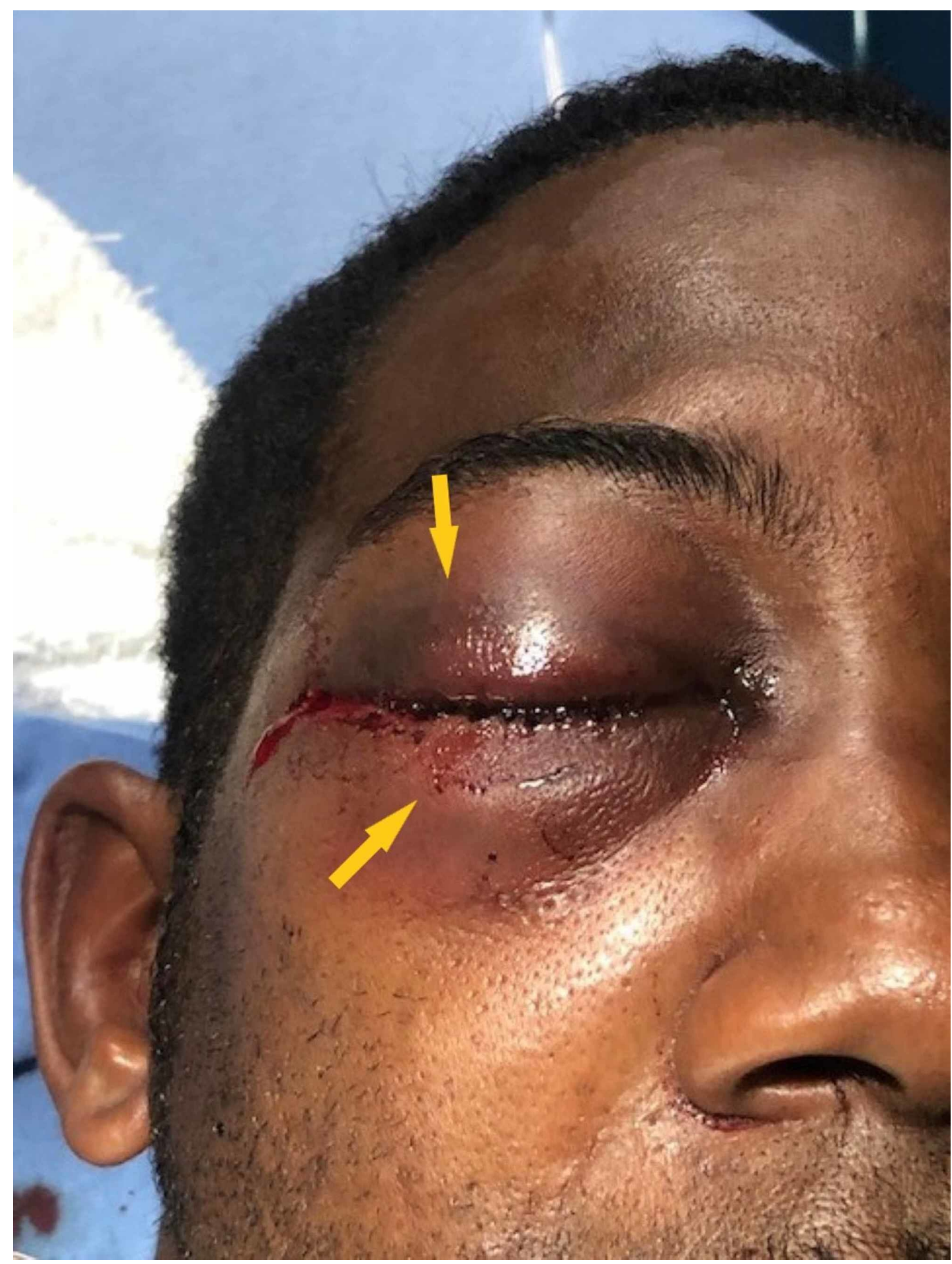

FIGURE 1: Patient with eyes closed, in position of comfort Arrows show periorbital swelling. 


\section{Cureus}

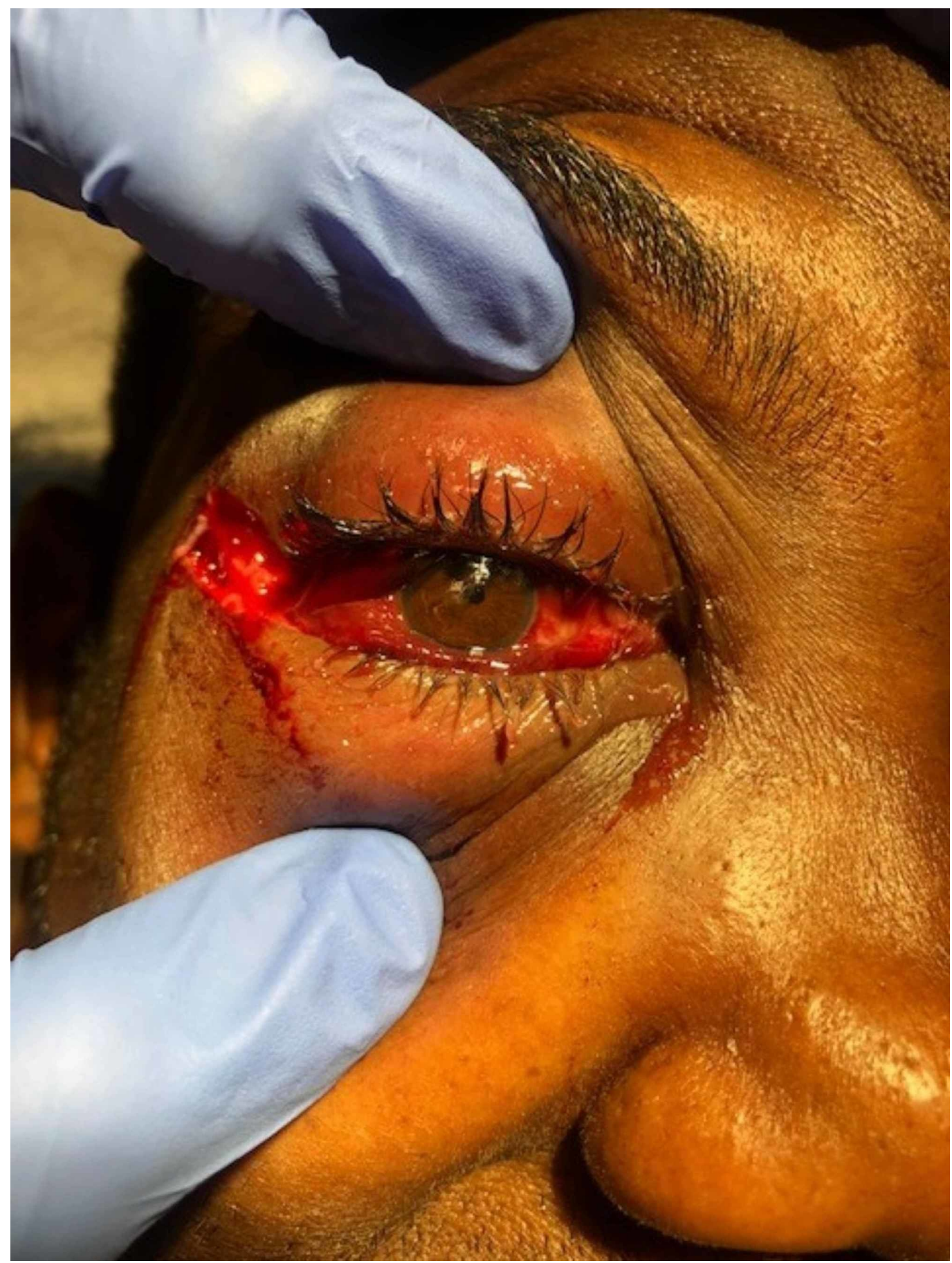

FIGURE 2: Patient with eye propped open by examiner

Computer Tomography (CT) scan of the head, orbits, and maxillofacial bones were obtained which revealed right exophthalmos with intraorbital fat stranding and abnormal caliber and density of the optic nerve sheath (Figure 3). The decision was made to transfer the patient to our facility for ophthalmology evaluation. 


\section{Cureus}

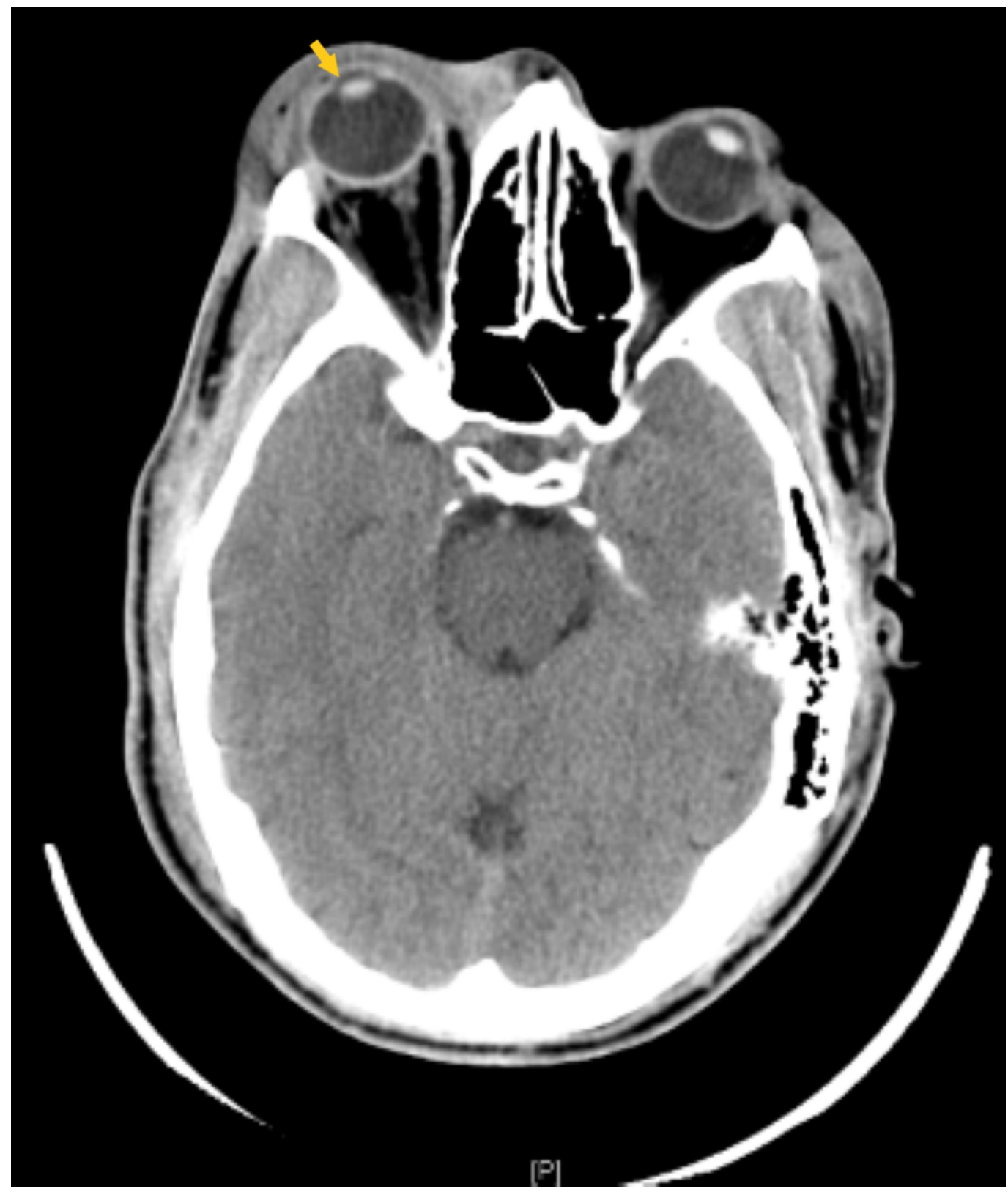

FIGURE 3: CT demonstrating right exophthalmos (arrow) with intraorbital fat stranding and abnormal caliber and density of the optic nerve sheath complex. Also seen is right preseptal subcutaneous soft tissue swelling and hematoma.

Upon talking with the transferring physician, we learned that the patient had nearly complete loss of vision in the affected eye. Knowing that orbital compartment syndrome can cause permanent ischemic changes as quickly as within 60 minutes of onset, my attending physician requested that a lateral canthotomy procedure be performed prior to transfer. We were able to walk the transferring physician through the procedure (Figure 4). 


\section{Cureus}

Performing a lateral canthotomy:

1. Inject $1-2 \mathrm{~mL}$ of $1 \%$ to $2 \%$ lidocaine with epinephrine into the lateral canthus of the affected eye.

2. Irrigate the eye with normal saline to flush any debris.

3. Establish hemostasis by gently crimping the lateral corner of the eye with a hemostat.

4. Raise the skin with forceps and then use scissors to make a 1 to $2 \mathrm{~cm}$ incision from the lateral corner of the eye extending laterally outward.

5. Direct the scissors along the lateral side of the orbital rim away from the globe, and cut the lateral canthus tendon inferiorly. Then, cut the superior crux of the lateral canthus tendon.

\section{FIGURE 4: Technique for performing lateral canthotomy}

A lateral canthal incision was made for lateral canthotomy (Figure 5). On the following day, the patient had complete restoration of his vision and was discharged home with ophthalmology follow up.

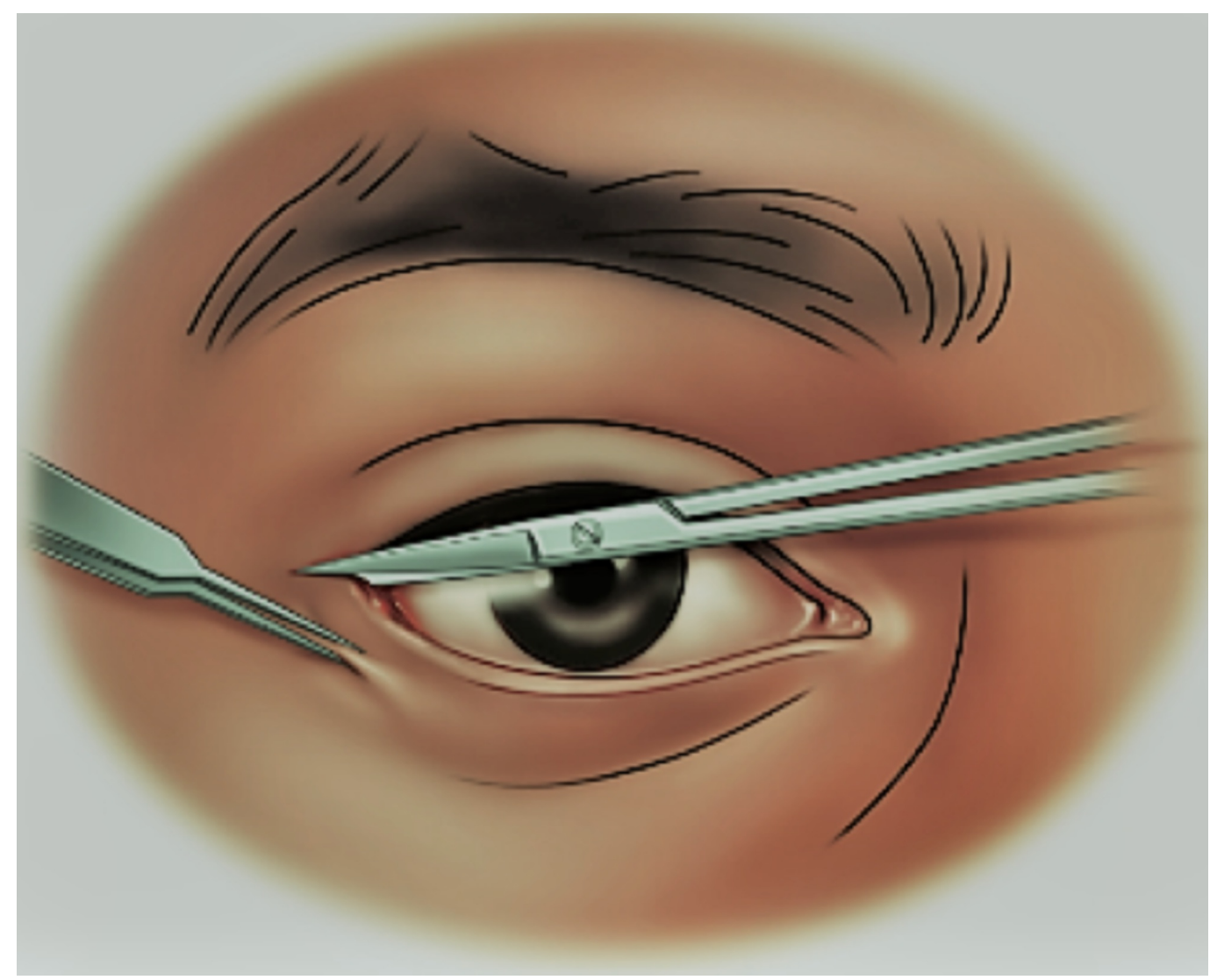

FIGURE 5: Cut for lateral canthotomy to reduce intraocular pressure

[3]

\section{Discussion}

Patients with orbital compartment syndrome may experience symptoms such as a sudden onset 
decrease in visual acuity associated with pain, proptosis, ophthalmoparesis, and a relative afferent pupillary defect [4].

The indications for performing a lateral canthotomy include: intraocular pressure greater than $40 \mathrm{~cm} \mathrm{H}_{2} \mathrm{O}$, trauma or orbital cellulitis with vision loss, and exophthalmos. From observing improvement in this patient's condition, it is emphasized that physicians should not wait for imaging to perform a lateral canthotomy, as permanent ischemic changes can occur within 60 minutes of onset.

The learning points are described as following: when performing a lateral canthotomy, start with the inferior canthal ligament; if this does not successfully reduce the proptosis then proceed with cutting the superior ligament as well. Repeat the intraocular pressure (IOP) measurement directly after the procedure.

In a sample of 190 emergency department physicians, 37.1\% indicated they would comfortably perform a lateral canthotomy, while $95.7 \%$ recognized permanent vision loss as a potential consequence of orbital compartment syndrome [5]. This case aims to reaffirm the sight-saving impact and importance of a lateral canthotomy for OCS.

\section{Conclusions}

Orbital compartment syndrome is an ophthalmologic emergency that requires immediate identification and treatment. Delaying treatment beyond one hour can put the patient at critical risk of permanent vision loss. A relatively simple procedure such as lateral canthotomy should be strongly considered as soon as possible to improve patients' conditions.

\section{Additional Information}

\section{Disclosures}

Human subjects: Consent was obtained by all participants in this study. Conflicts of interest: In compliance with the ICMJE uniform disclosure form, all authors declare the following: Payment/services info: All authors have declared that no financial support was received from any organization for the submitted work. Financial relationships: All authors have declared that they have no financial relationships at present or within the previous three years with any organizations that might have an interest in the submitted work. Other relationships: All authors have declared that there are no other relationships or activities that could appear to have influenced the submitted work.

\section{Acknowledgements}

This research was supported (in whole or in part) by Hospital Corporation of America Healthcare and/or Hospital Corporation of America (HCA) Healthcare affiliated entity. The views expressed in this publication represent those of the author(s) and do not necessarily represent the official views of HCA Healthcare or any of its affiliated entities.

\section{References}

1. Timlin HM, Bell SJ, Uddin JM, Osborne S: Treatment outcomes of lateral canthotomy and cantholysis for orbital compartment syndrome. Br J Oral Maxillofac Surg. 2019, 57:488-490. 10.1016/j.bjoms.2019.04.008

2. Rowh AD, Ufberg JW, Chan TC, Vilke GM, Harrigan RA: Lateral canthotomy and cantholysis: emergency management of orbital compartment syndrome. J Emerg Med. 2015, 48:325-330. 10.1016/j.jemermed.2014.11.002

3. Mahon BM, Desai BK: Lateral canthotomy. Atlas of Emergency Medicine Procedures. Ganti L 


\section{Cureus}

(ed): Springer, New York; 2016.

4. Sun MT, Chan WO, Selva D: Traumatic orbital compartment syndrome: importance of the lateral canthomy and cantholysis. Emerg Med Australas. 2014, 26:274-278. 10.1111/17426723.12236

5. Edmunds MR, Haridas AS, Morris DS, Jamalapuram K: Management of acute retrobulbar haemorrhage: a survey of non-ophthalmic emergency department physicians. BMJ. 2019, 36:245-247. 10.1136/emermed-2018-207937 